\title{
Scalp and Dura Matter Complex Reconstruction Using Free Anterolateral Thigh Flap with Vascularized Fascia
}

\author{
Masayuki Okochi*, Masanori Momiyama, Masaru Horikiri, Kazuku Ueda \\ Plastic and Reconstructive Surgery, Fukushima Medical University, Fukushima, Japan \\ Email: *oktms-okt@umin.ac.jp
}

Received 28 October 2015; accepted 29 February 2016; published 3 March 2016

Copyright (C) 2016 by authors and Scientific Research Publishing Inc.

This work is licensed under the Creative Commons Attribution International License (CC BY). http://creativecommons.org/licenses/by/4.0/

c) (i) Open Access

\begin{abstract}
The reconstruction of large scalp and dural defects is difficult. Anterolateral thigh (ALT) flap is now widely used because of its reliable blood supply to the skin paddle. Additionally, ALT can be harvested with a large skin paddle and large, well-vascularized fascia. We have successfully treated eight scalp and dural composite defect cases (five male and three female) using ALT with vascularized fascia. The patients' mean age was $59.1 \pm 20.4$ years ranging from 31 to 83 years. The mean dural defect size was $73 \pm 21 \mathrm{~cm}^{2}$, ranging from 50 to $120 \mathrm{~cm}^{2}$. There were no postoperative infections, bleeding, cerebrospinal fluid leakage, or meningitis. Further discussion about the usefulness of vascularized fascia may be required and we believe that plastic surgeons, head and neck surgeons, and neurosurgeons should report on the results of dural reconstruction.
\end{abstract}

\section{Keywords}

Dural Reconstruction, Vascularized Fascia, Anterolateral Thigh Flap

\section{Introduction}

The reconstruction of large scalp and dural defects is difficult and challenging [1]-[8]. The problem is what kind of material should be used to reconstruct large dural defects. The reconstruction of dural defects should be performed without cerebrospinal fluid (CSF) leakage or infection. However, we often experience cases that have already caused dural infection, and in such cases dural reconstruction should be performed using well-vascularized tissue. Koshima et al. reported the usefulness of anterolateral thigh flap (ALT) in the reconstruction of head and neck regions 9. ALT is now well known as a reliable vascularized flap for head and neck reconstruc-

${ }^{*}$ Corresponding author.

How to cite this paper: Okochi, M., Momiyama, M., Horikiri, M. and Ueda, K. (2016) Scalp and Dura Matter Complex Reconstruction Using Free Anterolateral Thigh Flap with Vascularized Fascia. Surgical Science, 7, 137-143.

http://dx.doi.org/10.4236/ss.2016.73018 
tion [7]-[12]. ALT can be harvested with a large skin paddle and a large, well-vascularized fascia [10]. We successfully controlled postoperative dural infection using vascularized fascia. In this report, we discuss our experience using free ALT in the reconstruction of composite defects of the scalp and dura matter.

\section{Material and Methods}

The subjects comprised eight patients (five male and three female) with a mean age of $59.1 \pm 20.4$ years who had undergone free ALT with vascularized fascia transfer for scalp and dural defects at Fukushima Medical University Hospital between April 2007 and April 2014.

\section{Surgical Procedure}

Artificial materials, tumors, devitalized tissues, and foreign bodies were removed by a neurosurgeon. ALT was harvested from the same side as the defect in seven of the eight patients. First, a linear incision was made into the fascia (Figure 1(a)). Next, the vascular pedicle was introduced to the outside through an incision (Figure 1(b)), then the incision was closed using 4-0 Neurolon (Ethicon Inc., Somerville, NJ) (Figure 1(c)). The fascia was fixed to the edge of the dura using 4-0 Neurolon. After fixation of the fascia, end-to-end anastomosis was performed between the lateral circumflex femoral artery and the superficial temporal artery under an operative microscope using 9-0 nylon (Keisei Medical Industry Co. Ltd., Tokyo, Japan). The lateral circumflex femoral vein was sutured to the superficial temporal vein using 9-0 nylon suture. The skin defect was covered by the skin paddle of ALT with 4-0 PDS II (Ethicon Inc., Somerville, NJ) and 5-0 Ethilon (Ethicon Inc., Somerville, NJ) (Table 1).

\section{Results}

Abscess formation related to artificial dura and artificial bone was observed in five of the eight patients. Necrosis of soft tissue tumors, which had invaded brain tissue, was observed in two patients, and one patient had bone and dural defects due to a severe head contusion caused by an industrial accident.

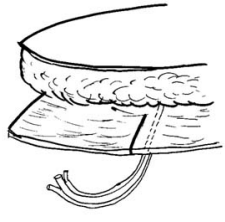

(a)



(b)



(c)

Figure 1. (a) To introduce the vascular pedicle to the outside, a liner incision was made into the fascia; (b) The vascular pedicle was introduced to the outside through the incision; (c) The incision was closed using 4-0 Neurolon.

Table 1. Patients profile.

\begin{tabular}{ccccc}
\hline Case & Age & Sex & Primary disease & Defect size of dura $(\mathrm{cm})$ \\
\hline 1 & 60 & F & Squamous cell carcinoma & 120 \\
2 & 31 & M & Trauma & 70 \\
3 & 86 & F & Infection of artificial bone and dura & 50 \\
4 & 59 & M & Infection of artificial bone and dura & 60 \\
5 & 72 & F & Infection of artificial bone and dura & 70 \\
6 & 40 & M & Neurofiboroma & 60 \\
7 & 83 & M & Infection of artificial bone and dura & 70 \\
\hline
\end{tabular}


Preoperatively, capsule formations under the artificial dura were observed in four of five cases that had preoperative subdural abscess formation. In these cases, the capsules were not removed. However, these cases had CSF leakage from the capsule. None of our cases experienced flap necrosis or leakage of CSF, postoperatively. Mean follow up period was 3.4 years ranging from 0.5 to 5 years. In Case 1, the recurrence of a brain tumor was observed two months postoperatively, and the patient died six months postoperatively.

\section{Case Report}

Case 1

A 60-year-old female presented with advanced squamous cell carcinoma in the left frontotemporal region. She had fallen into a fireplace and received severe a burn when she was six years old. The burn was healed with a conservative treatment. Five years preoperatively, ulceration of the burn scar occurred. However, she treated it herself and did not consult a doctor. She was referred from private clinic to our hospital when rapid growth and necrosis of the tumor was observed (Figure 2(a)). Wide excision of the tumor, skull, and dura was performed by a neurosurgeon and a plastic surgeon (Figure 2(b)). The size of the defect of the dura was $120 \mathrm{~cm}^{2}$. We harvested $20 \times 15 \mathrm{~cm}$ ALT with $15 \times 10 \mathrm{~cm}$ fascia (Figure 2(c) and Figure 2(d)). The flap was transferred to the

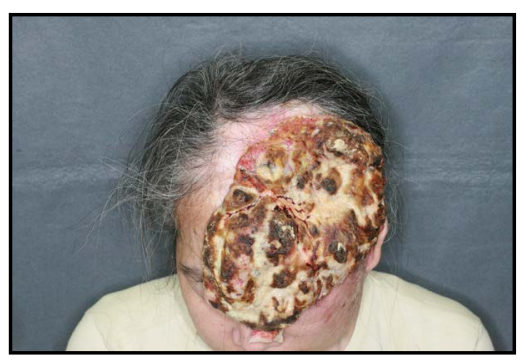

(a)

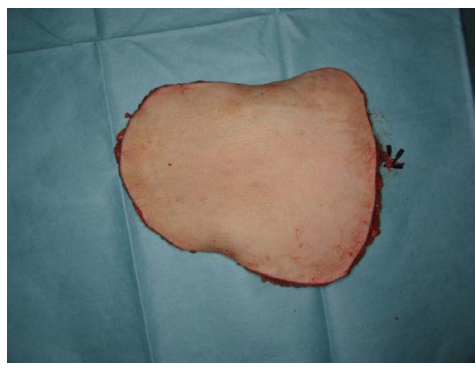

(c)

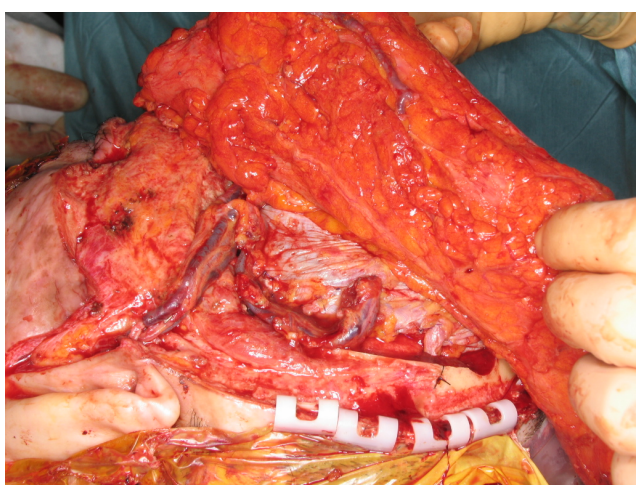

(e)

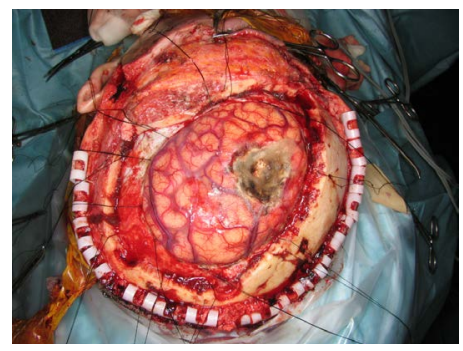

(b)

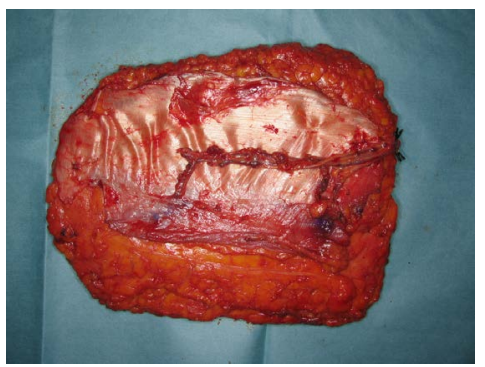

(d)



(f)

Figure 2. (a) Preoperative view of patient's forehead. A large and necrotic tumor was invaded the brain tissue; (b) Large dural defect occurred. Brain tissue and dura were excised by a neurosurgeon; (c) Anterolateral thigh flap was harvested. The size of the skin paddle was $25 \times 15 \mathrm{~cm}$; (d) Flap was harvested with fascia and two perforators. The size of the fascia was $120 \mathrm{~cm}^{2}$; (e) Vascularized fascia was fixed to the dura; (f) One month after surgery. 
defect site. The fascia was fixed to the edge of the dura (Figure 2(e)). End-to-end anastomosis was performed between the superficial temporal artery and the lateral circumflex femoral artery. End-to-end anastomosis was also performed between the superficial temporal vein and the lateral circumflex femoral vein. There was no CSF leakage, meningitis, or flap necrosis (Figure 2(f)). Two months postoperatively, a recurrence of the tumor was observed in the patient's brain. Although recurrence of the tumor was observed, the patient and her family were satisfied with the result of the surgery because they did not have to treat a large necrotic tumor. Six months postoperatively, she died of recurrence and metastasis of the brain tumor.

Case 2

A 31-year-old male presented with a severe contusion wound in the left temporal region. He worked at a small factory, where he hit his head on a machine because his left sleeve was caught by a roller. He was taken to our hospital by ambulance. He had an open skull fracture with a brain contusion (Figure 3(a) and Figure 3(b)).

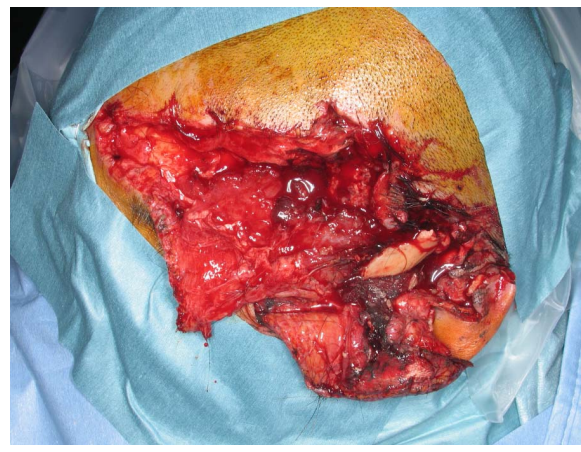

(a)

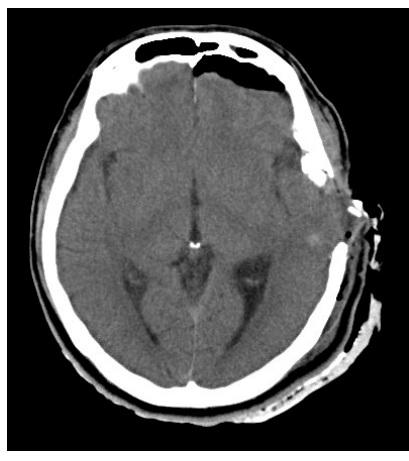

(b)



(c)



(e)



(d)



(g)

Figure 3. (a) Preoperative view of patient's left temporal head. Bone fragment, skin, hair and foreign bodies were observed; (b) Preoperative CT scan. Brain contusion was also observed; (c) Anterolateral thigh flap $(15 \times 10 \mathrm{~cm})$ was harvested; (d) The flap was harvested with vascularized fascia $(10 \times 10 \mathrm{~cm})$; (e) Vascualrized fascia was fixed to the dura; (f) Preoperative view of scar revision. Tissue expansion was successfully finished; (g) Final result. Two years after the primary surgery. One and half years after secondary surgery. Scar was acceptable. 
An emergency operation was performed to remove damaged scalp, temporal muscle, and skull fragments. Any oil and foreign bodies were also removed. The dural defect was $80 \mathrm{~cm}^{2}$, and we harvested $15 \times 10 \mathrm{~cm}$ ALT with $10 \times 10 \mathrm{~cm}$ fascia (Figure 3(c) and Figure 3(d)). The flap was transferred to the defect site and the fascia was fixed to the edge of the dura (Figure 3(e)). End-to-end anastomosis was performed both between the superficial temporal artery and the lateral circumflex femoral artery, and between the superficial temporal vein and the lateral circumflex femoral vein. There was no CSF leakage, meningitis, or flap necrosis. One month after surgery, he left hospital with no abnormal neurological findings. Eight months after surgery, we inserted a tissue expander into his scalp, three months after which we performed scar revision (Figure 3(f)). Two years postoperatively, the scar was acceptable (Figure 3(g)).

\section{Discussion}

Reconstruction of scalp, bone, and dural composite defects is challenging. This is because CSF leakage will cause wound infections, epidural abscesses or meningitis. In particular, many authors have reported the relationship between CSF leakage and postoperative meningitis [13]-[16].

The safety of artificial dura has been reported [18]. Neurosurgeons often perform dural reconstruction using artificial dural grafts such as polytetrafluoroethylene [17] [18], collagen matrix [19] and a cellular dermal matrix [20] after brain tumor resection. All of our cases had either a large scalp defect and abscess formation preoperatively, or a large contaminated wound. To prevent postoperative dural infection, we performed dural reconstruction using vascularized fascia.

There has been discussion about whether reconstructed dura should be vascularized. Nakano et al. performed dural reconstruction after the infection [21]. They also reported the safety of fascia lata graft. In their case, there was no large scalp defect, and they could perform direct closure of the scalp. On the other hand, Malliti et al. reported the results of dural reconstruction using artificial materials and pedicled fascial flap [1]. They concluded that using vascularized fascia could prevent CSF leakage and infection. Other studies have reported on the use of free flaps with vascularized fascia transfer for scalp and dural composite defects. The advantage of scalp and dural composite defect reconstruction using free flaps with fascia is that dead space can be filled with well-vascularized tissue so that there is no space between the fascia and the skin paddle. Recently, the usefulness of ALT for the reconstruction of head and neck defects has been reported. ALT can be harvested with large, well-vascularized fascia with large skin paddles. Some authors have reported scalp and dural complex defects using ALT with fascia. However, there are not many with more than five cases of dural reconstruction using vascularized fascia. In 2004, van Driel et al. reported an algorithm of scalp defect reconstruction after malignant tumor resection [22]. They suggested that ALT with fascia was the first choice for reconstruction of dural defects which had been previously irradiated to reduce postoperative infection. In our study, five cases had a subdural abscess formation preoperatively and two cases had a large malignant tumor with necrosis. One case had a large contaminated scalp, bone, dura, and brain wound. Nagasao et al. reported successful scalp and dural complex reconstruction without removing the capsule under the artificial dura [23]. In our study, capsule formation was observed in four cases. We also did not remove the capsule because all four cases had CSF leakage, and dural reconstructions were required. However, Fujioka et al. reported that preserving the capsule increased the risk of infection [24]. We believe that the use of well-vascularized fascia may be a solution to this issue. Abuzayed et al. performed duraplasty using autologous fascia lata reinforced by a pedicled temporoparietal fascia flap [25]. In their report, well-vascularized fascia could control CSF leakage. Of course, further discussion is needed and the necessity for vascularization of reconstructed dura should be investigated. Our results suggest that vascularized fascia prevents postoperative infection and CSF leakage. We also believe that plastic surgeons, head and neck surgeons, and neurosurgeons should report on the results of dural reconstruction. In addition, we should study more cases, and a multi-institutional joint research project is required.

\section{Conclusion}

We performed successful scalp and dural reconstruction using an ALT flap with vascularized fascia in patients with an epidural abscess or severe brain contusion preoperatively. We believe that more cases should be accumulated and the effectiveness of vascularized fascia should be investigated further. 


\section{References}

[1] Malliti, M., Page, P., Gury, C., Chomette, E., Natal, F. and Roux, F.K. (2004) Comparison of Deep Wound Infection Rates Using a Synthetic Dural Substitute (Neuro-Patch) or Pericranium Graft for Dural Closure: A Clinical Review of 1 Year. Neurosurgery, 54, 599-603. http://dx.doi.org/10.1227/01.NEU.0000108640.45371.1A

[2] Haddock, M.C., Creagh, T. and Sivarajan, V. (2011) Double-Free, Flow-Through Flap Reconstruction for Complex Scalp Defects: A Case Report. Microsurgery, 31, 327-330. http://dx.doi.org/10.1002/micr.20874

[3] Bondin, D. and Ross, G.L. (2011) The Use of a Combined Radial Forearm Flap and Radial Fascial Flap for Layered dural Lining and an Orbital Defect Reconstruction. Journal of Plastic and Reconstructive Aesthetic Surgery, 64, e167e169. http://dx.doi.org/10.1016/j.bjps.2010.12.026

[4] Guerrissi, J.O. (1999) Reconstruction of Large Defects in the Scalp with Fasciocutaneous Flaps. Scandinavian Journal of Plastic and Reconstructive Surgery and Hand Surgery, 33, 217-224. http://dx.doi.org/10.1080/02844319950159488

[5] Lutz, B.S., Wei, F.C., Chen, H.C., Lin, C.H. and Wei, C.Y. (1998) Reconstruction of Scalp Defects with Free Flaps in 30 Cases. British Journal of Plastic Surgery, 51, 186-190. http://dx.doi.org/10.1054/bjps.1997.0182

[6] Soon, S.K. and Hak, C. (2012) Staged Reconstruction of Infected Dura Mater Using Vascularized Rectus Abdominis Muscle. Journal of Craniofacial Surgery, 23, 1741-1743. http://dx.doi.org/10.1097/SCS.0b013e31825877ee

[7] Ozkan. O., Coskunfirat, O.K., Ozgentas, H.E. and Derin. A. (2005) Rationale for Reconstruction of Large Scalp Defects Using the Anterolateral Thigh Flap: Structural and Aesthetic Outcomes. Journal of Reconstructive Microsurgery, 21, 539-545. http://dx.doi.org/10.1055/s-2005-922433

[8] Shimizu, F., Oatari, M., Matsuda, K., Uehara, M., Sato, S. and Kato, Aiko. (2013) Algorithm for Reconstruction of Composite Cranial Defects Using the Fascial Component of Free Anterolateral Thigh Flaps. Journal of Craniofacial Surgery, 24, 1631-1635. http://dx.doi.org/10.1097/SCS.0b013e3182999a33

[9] Koshima, I., Fukuda, H., Yamamoto, H., Moriguchi, T., Soeda, S. and Ohata, S. (1993) Free Anterolateral Thigh Flaps for Reconstruction of Head and Neck Defects. Plastic and Reconstructive Surgery, 92, 421-428. http://dx.doi.org/10.1097/00006534-199309000-00005

[10] Koshima, I. (2000) Free Anterolateral Thigh Flap for Reconstruction of Head and Neck Defects Following Cancer Ablation. Plastic and Reconstructive Surgery, 105, 2358-2360. http://dx.doi.org/10.1097/00006534-200006000-00007

[11] Shieh, S.J., Chiu, H.Y., Shen, C.L., et al. (2000) Free Anterolateral Thigh Flap for Reconstruction of Head and Neck Defects Following Cancer Ablation. Plastic and Reconstructive Surgery, 105, 2349-2357. http://dx.doi.org/10.1097/00006534-200006000-00006

[12] Bo, B., Qun, Y., Zheming, P., Haitao, X. and Tianyi, L. (2011) Reconstruction Scalp Defects after Malignant Tumor Resection with Anterolateral Thigh Flaps. Journal of Craniofacial Surgery, 22, 2208-2211. http://dx.doi.org/10.1097/SCS.0b013e318231fdb2

[13] Sade, B., Oya, S. and Lee, J.H. (2011) Non-Watertight Dural Reconstruction in Meningioma Surgery: Results in 439 Consecutive Patients and a Review of the Literature. Clinical Article. Journal of Neurosurgery, 114, 714-718. http://dx.doi.org/10.3171/2010.7.JNS10460

[14] Bergermann, M., Donald, P.J. and Awengen, D.F. (1993) Management of Inflammatory Complications of Skull Base Surgery. Skull Base, 3, 7-10. http://dx.doi.org/10.1055/s-2008-1060558

[15] Horowitz, G., Fliss, D.M., Margalit, N., Wasserzug, O. and Gil, Z. (2011) Association between Cerebrospinal Fluid Leak and Meningitis after Skull Base Surgery. Otolaryngology Head and Neck Surgery, 145, 689-693. http://dx.doi.org/10.1177/0194599811411534

[16] Allen, K.P., Isaacson, B., Kutz, J.W., Purcell, P.L. and Roland, P.S. (2012) The Association of Meningitis with Postoperative Cerebrospinal Fluid Fistula. Journal of Neurological Surgery Skull Base, 73, 401-404. http://dx.doi.org/10.1055/s-0032-1329618

[17] Shimizu, S., Koizumi, H., Kurita M., Utsuki, S., Oka, H. and Fuji, K. (2007) Duraplasty in the Posterior Fossa Using a Boat-Shaped Sheet of Expanded Polytetrafluoroethylene. Neurologia Medico-Chirurgica, 47, 379-381. http://dx.doi.org/10.2176/nmc.47.379

[18] Yamada, K., Miyamoto, S., Nagata, I., Kikuchi, H., Ikada, Y., Iwata, H. and Yamamoto, K. (1997) Development of a Dural Substitute from Synthetic Bioabsorbable Polymers. Journal of Neurosurgery, 86, 1012-1017. http://dx.doi.org/10.3171/jns.1997.86.6.1012

[19] Costantino, P.D., Wolpoe, M.E., Govindaraj, S., Chaplin, J., Sen, C., Cohen, M. and Gnoy, A. (2000) Human Dural Replacement with Acellular Dermis: Clinical Results and Review of the Literature. Head and Neck, 22, 765-771. http://dx.doi.org/10.1002/1097-0347(200012)22:8<765::AID-HED4>3.0.CO;2-7

[20] Balasubramanian, C., Coley, E. and Whittle, I.R. (2009) Dural Bridge Sutures to Prevent Sinking of Dural Substitutes: Technical Note. Acta Neurochirurgia, 151, 155-157. http://dx.doi.org/10.1007/s00701-008-0167-3 
[21] Nakano, T., Yoshikawa, K., Kunieda, T., Arakawa, Y., Kikuchi, T., Yamawaki, S., Naitoh, M., Kawai, K. and Suzuki, S. (2014) Treatment for Infection of Artificial Dura Mater Using Free Fascia Lata. Journal of Craniofacial Surgery, 25, 1252-1255. http://dx.doi.org/10.1097/SCS.0000000000000929

[22] van Driel, A.A., Mureau, M.A., Goldstein, D.P., Gilbert, R.T., Irish, J.C., Gulane, P.J., Neligan, P.C. and Hofer, S.Q. (2010) Aesthetic and Oncologic Outcome after Microsurgical Reconstruction of Complex Scalp and Forehead Defects after Malignant Tumor Resection: An Algorithm for Treatment. Plastic and Reconstructive Surgery, 126, 460-470. http://dx.doi.org/10.1097/PRS.0b013e3181de2260

[23] Nagasao, T., Shinoda, J., Horiguchi, T. and Kishi, T. (2011) Capsule Formation Can Make Secondary Reconstruction of the Dura Mater Unnecessary after Cranial Infection. Journal of Craniofacial Surgery, 22, 84-88. http://dx.doi.org/10.1097/SCS.0b013e3181f6c587

[24] Fujioka, M., Hayashida, K., Murakami, C. and Koga, Y. (2012) Preserving Capsule Formation after Removal of Dura Mater Complex Increases Risk of Cranial Infection Relapse. Journal of Craniofacial Surgery, 23, 1579-1580. http://dx.doi.org/10.1097/SCS.0b013e3182541f2c

[25] Abuzayed, B., Kafadar, A.M., Oğuzoğlu, S.A., Canbaz, B. and Kaynar, M.Y. (2009) Duraplasty Using Autologous Fascia Lata Reenforced by On-Site Pedicled Muscle Flap: Technical Note. Journal of Craniofacial Surgery, 20, 435438. http://dx.doi.org/10.1097/SCS.0b013e31819b968f 